\title{
Peningkatan Kompetensi Bagi Siswa Melalui Pelatihan dan Pendampingan Jaringan Komputer Pada Sekolah Menengah Kejuruan Ma'arif NU 1 Karanglewas Purwokerto
}

\author{
Mohammad Imron*1, Dwi Krisbiantoro², Primandani Arsi ${ }^{3}$ \\ 1,23Program Studi Informatika, Fakultas Ilmu Komputer, Universitas Amikom Purwokerto \\ *e-mail: imron@amikompurwokerto.ac.id ${ }^{1}$,dwikris@amikompurwokerto.ac.id ${ }^{2}$, \\ ukhti.prima@amikompurwokerto.ac.id ${ }^{3}$
}

\begin{abstract}
With the development of technology in the era of the industrial revolution 4.0 which is increasing drastically, students are required to keep up with technological developments, mastery of ICT has become a very important subject at the primary and secondary level. Computer network engineering study program SMK-IT Ma'arif NU 1 Karanglewas in the teaching and learning process of following the curriculum according to government standards, based on existing problems students are only given material limited to basic knowledge about competence, not equipped with practicum that should be obtained by students. The purpose of this activity is to provide training to participants on the configuration of computer networks that have not been taught before, it is hoped that the training can improve the skills of participants. The method of implementation uses several stages of material delivery from the modules provided during the practice and evaluation. The results of the implementation of all the activities found that the community service training program for students went well, among others, 30 students participated in the evaluation of practicum material with an average value of $88 \%$.
\end{abstract}

Keywords: Computer Networks, Training, Students, Industrial Revolution 4.0, Configuration

\begin{abstract}
Abstrak
Dengan perkembangan teknologi di era revolusi industri 4.0 yang semakin meningkat dratis siswasiswi dituntut harus tetap mengkuti perkembangan teknologi, penguasaan TIK menjadi sangat penting mata pelajaran pada tingkat sekolah dasar maupun sekolah menengah. Program studi teknik jaringan komputer SMK-IT Ma'arif NU 1 Karanglewas dalam proses belajar mengajar mengkuti kurikulum sesuai standar pemerintah, berdasarkan permasalahan yang ada siswa hanya diberi materi sebatas pengetahuan dasar mengenai kompetensi, tidak dilengkapi praktikum yang seharusnya didapatkan siswa-siswi. Tujuan dari pelaksanaan kegiatan ini untuk memberikan pelatihan kepada peserta mengenai konfigurasi jaringan komputer yang sebelumnya belum pernah diajarkan, diharapkan dengan adanya pelatihan dapat meningkatkan keterampilan peserta. Metode pelaksanaan menggunakan beberapa tahapan penyampaian materi dari modul yang diberikan pada saat praktek dan melakukan evaluasi. Hasil pelaksanaan dari semua kegiatan didapat bahwa pelatihan program pengabdian masyarakat kepada siswa-siswa berjalan dengan baik, antusia yang diikuti 30 siswa-siswi dengan pencapaian evaluasi materi praktikum nilai rata-rata $88 \%$.
\end{abstract}

Kata kunci: Jaringan Komputer, Pelatihan, Siswa-Siswi, Revolusi Industri 4.0 , Konfigurasi

\section{PENDAHULUAN}

Penguasaan bidang teknologi khususnya bidang Teknologi Informasi dan Komunikasi (TIK) di era Revolusi Industri 4.0. Teknologi informasi merupakan studi penggunaan peralaatan elektronika terutama komputer dan untuk menyimpan, menganalisis serta menampilkan gambar maka teknologi informasi dibutuhkan di era sekarang ( Kadir, 2013) yang merupakan syarat bagi siswa-siswa SMK agar tetap dapat mengikuti perkembangan teknologi yang begitu pesat. Jenjang pendidikan secara sektor saat ini dan masa yang akan datang mulai berorientasi kepada perubahan global dan perkembangan teknologi informasi, ilmu pengetahuan, seni dan budaya. Penguasaan TIK menjadi sangat penting karena setiap pihak yang terlibat didalamnya di tuntut juga untuk berpartisipasi secara aktif, pemerintah kini telah menjadikan TIK mata pelajaran wajib pada tingkat sekolah dasar maupun sekolah menengah. 
Program studi Teknik Komputer Jaringan di SMK-IT Ma'arif NU 1 Karanglewas Purwokerto dalam proses belajar mengajar mengikuti kurikulum sesuai dengan standard pemerintah, sehingga siswa-siswi memiliki kemampuan dasar instalasi sistem operasi dan jaringan komputer. Mengingat saat ini pendidikan di bidang ilmu komputer yang berkembang pesat dalam tingkat sekolah menengah menjadi tantangan bagi lulusan SMK dikarenakan banyaknya kompetitor akan persaingan baik dari SMK maupun dari tingkat lulusan perguruan tinggi. Secara umum siswa-siswa SMK sendiri memiliki pengetahuan umum tentang arsitektur jaringan, topologi jaringan, pengalamatan IP address, pemahaman Mikrotik, pengkabelan, dan setting Mikrotik, sehingga siswa-siswi juga memperoleh pengetahuan dalam bidang wirausaha yang dapat dari bangku sekolah (Pardede,2016).

Jaringan komputer merupakan perpindahan dari suatu komputer ke suatu sumber (trasmiter) ke komputer tujuan (receiver) yang dilaluinya hingga media pengantar pengiriman dalam bentuk bit-bit, salah satu contoh jaringan komputer yaitu video conference pada komputer yang mana video akan diolah kedalam bit-bit yang memasuki media penghantar untuk selanjutnya di komunikasikan (Stalling, 2015). Dalam proses pembelajaran mata pelajaran Jaringan Komputer selama ini selalu menggabungkan antara teori dengan perangkat keras, sehingga siswa menguasai teori dan proses selanjutnya siswa mempraktikan dengan perangkat jaringan komputer. Dari sisi praktik terkadang siswa mengalami kendala dikarenakan peralatan dan bahan kebutuhan praktikum tidak memenuhi dengan baik yang harganya relatif mahal. Dari permasalahan tersebut akibatnya praktik gagal dikarenakan teori dan praktik berbeda dengan yang dipelajari, hal ini menyebabkan terjadinya kelemahan dalam kompetensi yang diharapkan.

Hasil observasi bahwa kemampuan siswa-siswi dalam kemampuan dasar untuk membangun jaringan komputer serta pengetahuan dalam bidang tersebut maka siswa-siswi sangat berpotensi untuk dikembangkan kemampuan atau keterampilan membangun infrastruktur jaringan komputer dan internet sebagai dasar jiwa kewirausahaan siswa SMK (Maulita, dkk. 2017). Berdasarkan latar belakang tersebut maka permasalahan mitra yang ditemukan adalah pembelajaran yang diajarkan oleh guru hanya sebatas pengetahuan dasar mengenai kompetensi yang harus dikuasai siswa-siswi, selain minimnya peralatan dan pengetahuan karena keterbatasan SDM maupu sarana prasarana maka solusinya dengan memberikan pelatihan, dan pendampingan kepada siswa-siswi untuk meningkatkan kompetensi jaringan komputer berbasis ICT maupun membangun jaringan internet (Irawan, 2016). Mengingat untuk sekarang perkembangan jaringan internet dan komunikasi sangat pesat, kegiatan pengabdian masyarakat ini akan dititik beratkan pada bagaimana membangun infrastruktur jaringan internet, arsitektur, sejarah, dan standarisasi jaringan berdasarkan trend (Sukaridhoto, 2014).

Sehingga dengan dengan era revolusi industri 4.0 ini telah mendisrupsi hampir semua bidang ilmu dan lini kehidupan, maka SMK-IT Ma'arif $\mathrm{Nu} 1$ Karanglewas harus mengetahui perkembangan teknologi mengenai internet of thing khususnya teknik komputer dan jaringan agar dapat mengikuti tren perkembangan dari pemanfaatan internet yang sekarang (Sasmito, 2020)

\section{METODE}

Sasaran kegiatan sendiri adalah siswa-siswi SMK-IT Ma'arif 1 Karanglewas Purwokerto yang perlu pengoptimalan dan sentralisasi data sehingga dibutuhkan pelatihan dan pendampingan dalam membangun infrastruktur jaringan komputer. Untuk metode pelaksanaan kegiatan menjelaskan tahapan atau langkah-langkah dalam melaksanakan solusi yang ditawarkan untuk mengatasi permasalahan dilaksanakan dalam beberapa tahap (Faradisa, 2015), yang digambarkan pada gambar 1 . 


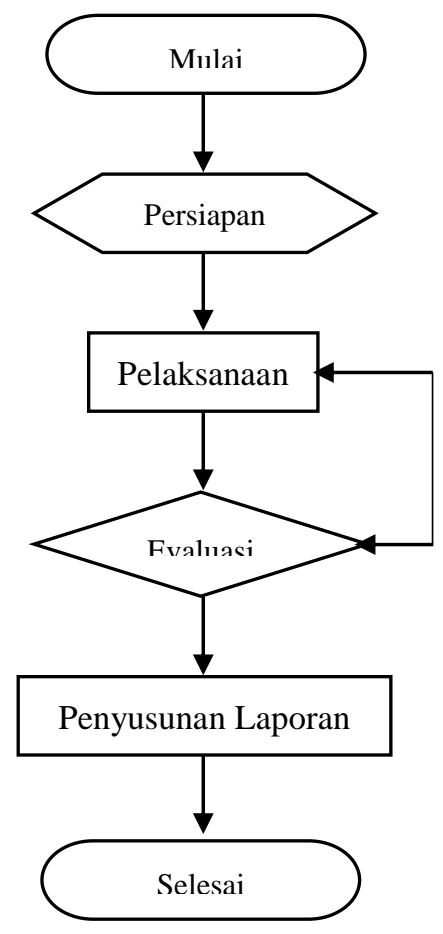

Gambar 1. Flowchart Kegiatan Pengabdian

\section{Persiapan Kegiatan Pelatihan}

Melakukan survei lokasi pelaksanaan kegiatan pengabdian dalam hal ini SMK-IT Ma'arif $\mathrm{Nu} 1$ Karanglewas dan tempat pelaksanaan

$>$ Mewancarai kepala sekolah SMK-IT Ma'arif Nu 1 Karanglewas yaitu Bapak H. kodir, SHI, M.Pd. dengan tujuan untuk mengumpulkan data siswa-siswi yang akan mengikuti pelatihan dan kebutuhan apa yang akan dilakukan sebagai bahan pelatihan

$>$ Pembuatan bahan ajar atau modul praktikum sebagai refernsi siswa-siswi selama pelatihan.

$>$ Evaluasi kegiatan selama pelatihan serta bimbingan atau konsultasi.

\section{HASIL DAN PEMBAHASAN}

Pelatihan ini dilakukan di STMIK AMIKOM Purwokerto pada Laboratorium Komputer dengan jumlah peserta 30 siswa-siswi SMK-IT Ma'arif NU 1 Karanglewas pada tanggal 16 -20 April 2018. Sosialisasi untuk siswa sendiri dilakukan sebelum pelaksanaan dilakukan dengan menjelaskan materi seputar lingkup ilmu komputer yang menjadi bahan bagi mereka untuk bisa diterapkan dengan materi yang selama ini dipelajari pada tingkat SMK. Sedangkan hal-hal yang diberikan saat diberikan pada sosialisasi ini diantaranya tentang pelatihan bagaimana cara instalasi sistem operasi, cara merakit kabel, mengkoneksi LAN dan Access point. 
Untuk menghasilkan pelatihan dan pendampinga jaringan komputer ini menggunakan metode pelatihan langsung berupa pemaparan atau presentasi, penyediaan tutorial serta diskusi yang tergambar pada gambar 2 . dan gambar 3 .

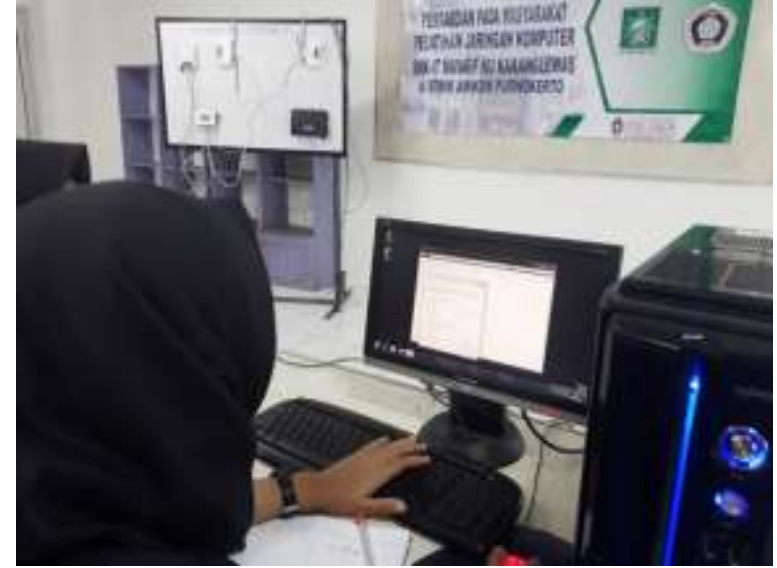

Gambar 2. Peserta pelatihan Jaringan Komputer ketika sedang Setting IP Address

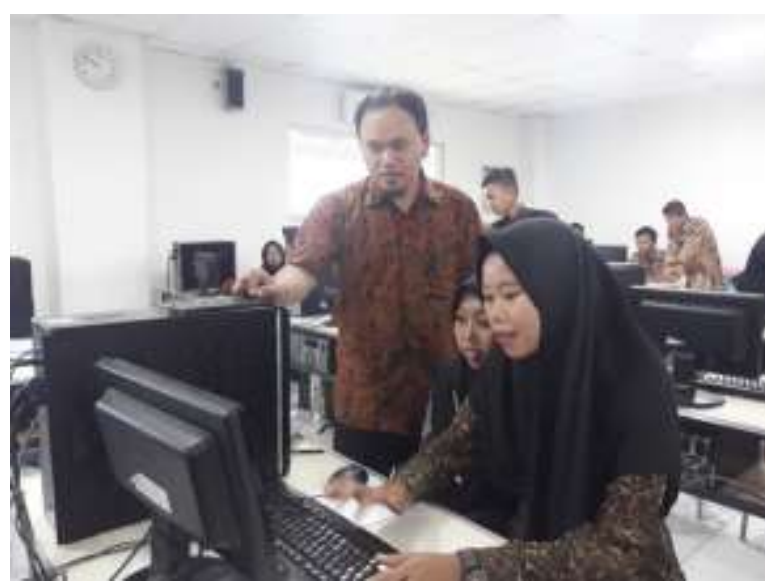

Gambar 3. Peserta Pelatihan Jaringan Komputer ketika sedang menerima materi/diskusi

Materi dijelaskan dengan rangkaian penjelasan mengenai jaringan komputer dan materi tersebut juga langsung dipraktikan oleh siswa-siswi yang mengikutinya, sesi pemaparan juga diselingi tanya jawab siswa diberikan kesempatan untuk mengajukan pertanyaan, hal tersebut cukup terlihat pada situasi pelatihan secara langsung yang dilaksanakan selama 5 hari. Dari pelatihan yang dilakukan siswi mengikuti dengan baik sebagaimana pada bambar 4 dan 5 .

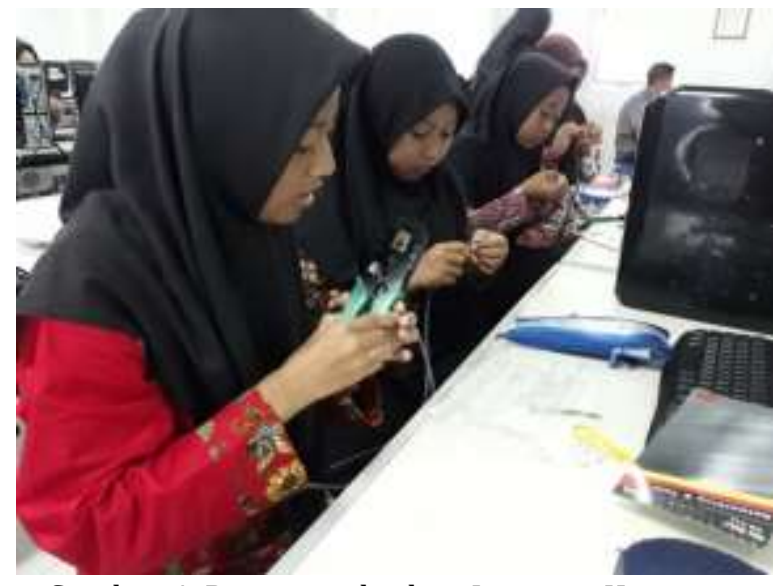

Gambar 4. Peserta pelatihan Jaringan Komputer ketika sedang Konfigurasi Kabel

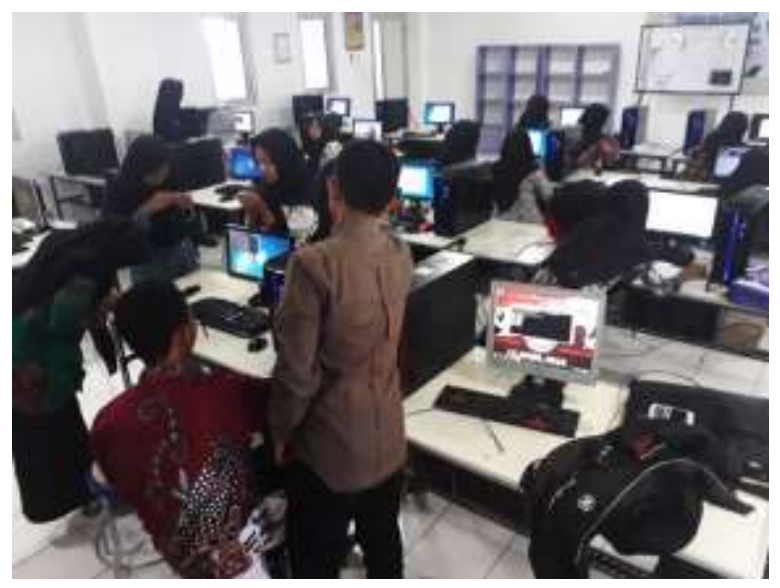

Gambar 5. Peserta Pelatihan Jaringan Komputer ketika sedang instalasi sistem operasi

Manfaat dari pelatihan ini diantaranya untuk melatih siswa-siswi yang tidak paham tentang jaringan komputer, konfigurasi maupun konfigurasi access point, dengan pelatihan ini juga dilakukan evaluasi yang mana hasil dari pelatihan siswa-siswi menjadi paham dan langsung dapat mengimplementasikan. Dari kegiatan selama pelatihan materi yang disampaikan meliputi berbagai macam materi dari dasar sebelum konfigurasi mikrotik dan access point dan untuk lebih jelasnya dapat dilihat pada tabel 1. 
Tabel 1. Pelaksanaan Kegiatan Pelatihan

\begin{tabular}{|c|c|c|}
\hline No. & Hari & Materi \\
\hline 1. & Senin & $\begin{array}{l}\text { Pelatihan perakitan komputer, instalasi sistem operasi, } \\
\text { dan konfigurasi interface }\end{array}$ \\
\hline 2. & Selasa & $\begin{array}{l}\text { Pelatihan pengkabelan, konfigurasi IP Address Gateway, } \\
\text { DNS Server, DHCP dan subnetting }\end{array}$ \\
\hline 3. & Rabu & Pelatihan membangun Server \\
\hline 4. & Kamis & Pelatihan konfigurasi mikrotik \\
\hline 5. & Jum'at & Pelatihan Access point dan evaluasi \\
\hline
\end{tabular}

Selama pelatihan 5 hari ini siswa-siswi mendapatkan materi baru yang belum didapatkan di sekolah, sehingga antusias dalam mengikuti pelatihan. Selain dari kegiatan itu kami diminta untuk memberikan motivasi kepada siswa-siswi jurusan TKJ pada SMK-IT Ma'arif $\mathrm{Nu} 1$ Karanglewas agar setelah lulus diharapkan siswa dapat melanjutkan ke perguruan tinggi.

Evaluasi kegiatan berupa mengerjakan dan mempraktikan secara langsung menggunakan alat-alat yang telah disediakan sebagai bahan evaluasi selama pelatihan, analisa data berupa pertanyaan yang diajukan kepada siswa-siswi yang telah mengikuti selama pelatihan, diatara pertanyaan tentang pemahaman dasar jaringan siswa setalah mengikuti pelatihan hasilnya dengan rata-rata keseluruhan materi dan praktik $88 \%$ siswa selama pelatihan.

Dari kegiatan pelatihan yang telah dilakukan berjalan dengan lancar yang diindetifikasi diantaranya antusiasme para peserta pelatihan dan dukungan dari SMK-IT Ma'arif $\mathrm{Nu} 1$ Karanglewas, dalam kegiatan pengabdian yang dilakukan berkaitan dengan materi yang diberikan dan dilakukan evaluasi secara langsung dapat dilihat persentase hasil pelatihan selama 5 hari dan dapat dilihat di tabel 2.

Tabel 2. Persentase Materi dan Praktik

\begin{tabular}{clrr}
\hline No. & \multicolumn{1}{c}{ Bahasan Materi dan Praktik } & Selesai & $\begin{array}{r}\text { Persentase } \\
(\%)\end{array}$ \\
\hline 1. & Perakitan Komputer & 30 & $100 \%$ \\
2. & Instalasi Sistem Operasi & 28 & $93 \%$ \\
& Konfigurasi Pengkabelan dan Konfigurasi IP & & \\
3. & Address & 30 & $100 \%$ \\
4. & Konfigurasi Server & 26 & $87 \%$ \\
5. & Konfigurasi Mikrotik & 21 & $70 \%$ \\
6. & Konfigurasi Acces Point dan Evaluasi & 23 & $77 \%$ \\
\hline & & Rata-rata Persentase & $88 \%$ \\
\hline
\end{tabular}

Dari hasil kegiatan pelatihan ini diharapkan dapat memberikan manfaat bagi para siswasiswi, khususnya SMK-IT Ma'arif Nu 1 Karanglewas, manfaat lain dari pelatihan ini antara lain melatih siswa-siswi yang tidak dapat mengerti menjadi paham tentang konfigurasi jaringan komputer, sehingga dapat memotivasi untuk lebih giat lagi dalam belajar. 


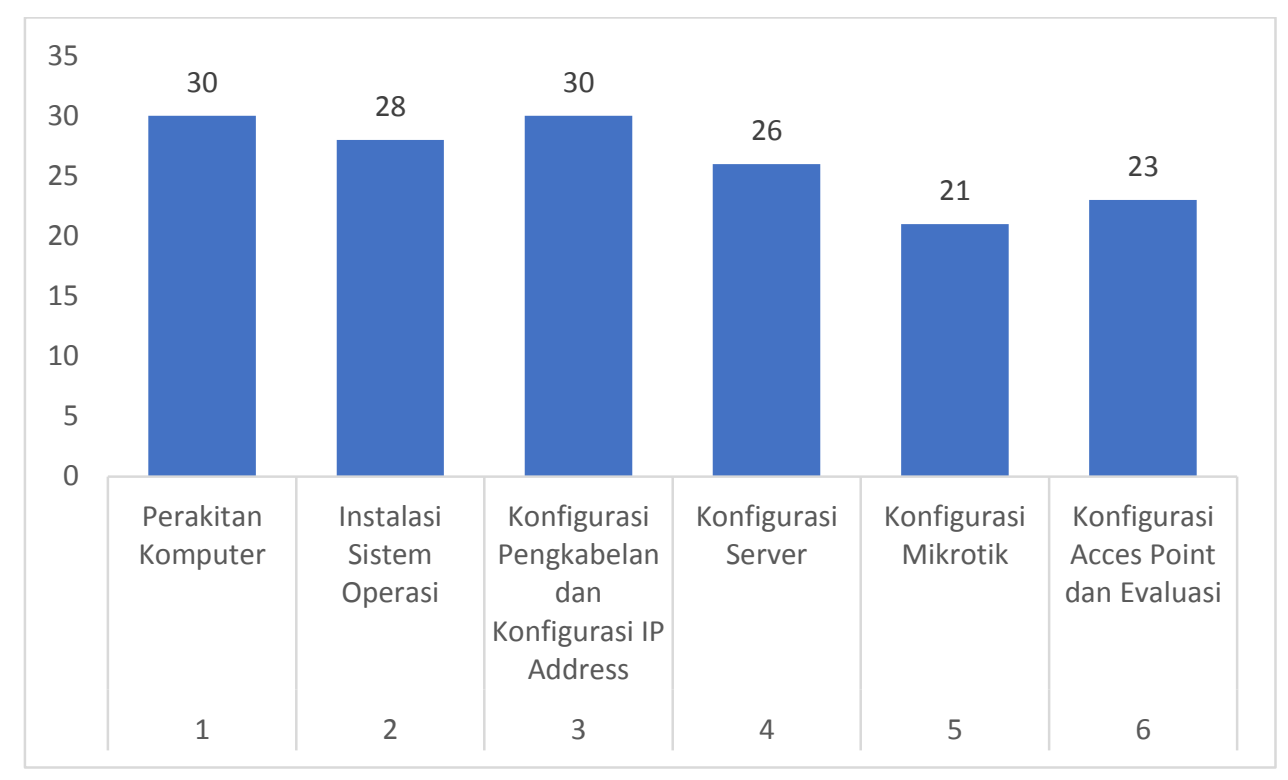

Gambar 6. Grafik Persentase Hasil Evaluasi Siswa-Siswi SMK-IT Ma'arif Nu 1 Karanglewas

\section{KESIMPULAN}

Kesimpulan dari kegiatan pengabdian kepada masyarakat yang telah dilakukan dan telah memberikan hasil yang diperoleh siswa-siswi diantaranya:

1. Dari hasil wawancara dan observasi pada saat pelatihan bahwa didapatkan program pengabdian masyarakat ini memberikan manfaat yang baik terutama siswa-siswi SMK-IT Ma'arif Nu 1 Karanglewas.

2. Kegiatan pengabdian yang telah dilakukan dengan jumlah perserta sebanyak 30 siswa-siswi SMK-IT Ma'arif $\mathrm{Nu} 1$ Karanglewas meningkat dalam keterampilan mengkonfigurasi jaringan komputer baik itu konfigurasi Server maupun Access Point dengan persentasi rata-rata $88 \%$

\section{UCAPAN TERIMA KASIH}

Ucapan terima kasih kami sampaikan kepada Yayasan SMK-IT Ma'arif Nu 1 Karanglewas dan Kepala Sekolah yang telah mempercayakan siswa-siswinya kepada kami, sehingga dengan adanya program pengabdian masyarakat ini kami dapat memberikan bekal materi untuk siswasiswa dengan hasil yang memuaskan.

\section{DAFTAR PUSTAKA}

Abdul Kadir \& Terra Ch. Triwahyuni. (2013). Pengenalan Teknologi Informasi. Yogyakarta.

A. M. H. Pardede And Novriyenni. (2016). "Pelatihan Perakitan Komputer, Install Sistem Operasi Dan Pemasangan Jaringan Lokal Dan Internet Untuk Membangunjaringan Warnet, Perkantoran Dan Internet Desa Dalam Meningkatkan Kemandirian Siswa Smk Tunas Pelita Dan Smk Abdi Negara Kota Binjai," Techsi-Jurnal Tek. Inform., Vol. 8, No. 2, Pp. 18-25.

Stallings William. (2015). Data and Computer Communications. (10th Edition). Pearson Education Limited. Januari.

Maulita, Y., \& Lumbanbatu, K. (2017). Pelatihan Teknisi Jaringan Internet Untuk Meningkatkan Jiwa Kewirausahaan Siswa SMK,. Jurnal Teknik Informatika Kaputama (JTIK).,Vol.1, No.2, Juli 2017. 
I. S. Faradisa, Y. Wahyuni, and F. T. Industri. (2015). "IBM Pelatihan dan Pendampingan Pembuatan Media Pembelajaran Interaktif untuk Guru Sekolah," Pros. Semin. Nas., pp. 270277.

Irawan, K. (2016). Pelatihan Dan Instalasi Jaringan Lan (Local Area Network) Untuk Guru-Guru di Yayayasan Perguruan Birrul Walidain Semplak Bogor,. Jurnal Adbdimas, Volume 2. Nomer 2, Maret 2016.

Sukaridhoto, S., (2014). Buku Jaringan Komputer I,. Politeknik Elektronika Negeri Surabaya (PENS) -2014.

Ebook gratis jaringan Komputer, Universitas Mercu Buana Yogyakarta. (2019)., from http://blog.mercubuana-yogya.ac.id/

Sasmito, G., W, dkk (2020). Studi Pengenalan Internet of Things Bagi Guru dan Siswa SMK Bina Nusa Slawi Sebagai Wawasan Salah Satu Ciri Revolusi Industri 4.0., DINAMISA: Jurnal Pengabdian Kepada Masyarakat., Vol. 4, No.1. Maret 2020.

Madcoms. (2009). "Membangun Sistem Jaringan Komputer", Yogyakarta, Andi Publisher. 